\title{
Analysis of the implementation of ergonomic design at the new units of an oil refinery
}

\author{
Carolina Reich Marcon Passero a,b*, Érika Lye Ogasawara ${ }^{\mathrm{b}}$, Lucy Mara Silva Baú ${ }^{\mathrm{a}, \mathrm{b}}$, Sandro Artur Bu- \\ so $^{\mathrm{a}}$, Marcos Cesar Bianchi ${ }^{\mathrm{a}}$ \\ ${ }^{a}$ Petrobras, Petróleo Brasileiro SA. Refinaria Presidente Getúlio Vargas. Rod. do Xisto BR 476, km 16, CEP \\ 83707.440 - Araucária - PR - Brasil. \\ ${ }^{\mathrm{b}}$ Fisiotrab Ergonomia, Saúde e Segurança no Trabalho. Av. Getúlio Vargas, 2932, CEP 80240.040. Curitiba - PR \\ - Brasil.
}

\begin{abstract}
Ergonomic Design is the adaptation of working conditions to human limitations and skills in the physical design phase of a new installation, a new working system, or new products or tools. Based on this concept, the purpose of this work was to analyze the implementation of ergonomic design at the new industrial units of an oil refinery, using the method of Ergonomic Workplace Assessment. This study was conducted by a multidisciplinary team composed of operation, maintenance and industrial safety technicians, ergonomists, designers and engineers. The analysis involved 6 production units, 1 industrial wastewater treatment unit, and 3 utilities units, all in the design detailing phase, for which 455 ergonomic requirements were identified. An analysis and characterization of the requirements identified for 5 of the production units, involving a total of 246 items, indicated that $62 \%$ were related to difficult access and blockage operations, while $15 \%$ were related to difficulties in the circulation of employees inside the units. Based on these data, it was found that the ergonomic requirements identified in the design detailing phase of an industrial unit involve physical ergonomics, and that it is very difficult to identify requirements related to organizational or cognitive ergonomics.
\end{abstract}

Keywords: Designs, Petrochemistry, Ergonomic Workplace Assessment, Electronic Template

\section{Introduction}

Brazil's oil sector has been expanding its operations, led by Petrobras, the largest oil company in Latin America, which is expected to rank among the world's five largest integrated oil companies by 2020 . A publicly traded corporation whose majority shareholder is Brazil's Federal Government, Petrobras operates in the following sectors: exploration and production, refining, oil and natural gas trade and transportation, petrochemicals, and derivatives, electric energy, biofuel and the distribution of energy from other renewable sources [1]. In view of the importance of the petrochemical industry in Brazil, it is essential that, in addition to the quality of its products, the company should be concerned with the wellbeing of the employees that generate this wealth [2]. Thus, the implementation of ergonomics in the various activities involved in the petrochemical sector is extremely important.

According to Iida [3], ergonomic design involves the adaptation of working conditions to human characteristics in the design of a product, machine, environment or system. This would be a privileged situation, since it would allow for the examination of a wide range of alternatives. However, whoever analyzes and proposes recommendations must be knowledgeable about causes, since the real situation does not yet exist and the analysis is performed based on hypothetical situations. These situations can be compared with real conditions; moreover, today's advances in graphic computation allow for 3D simulations of design scenarios [3].

\footnotetext{
${ }^{*}$ Corresponding author. E-mail: carolina.marcon.fisiotrab@petrobras.com.br.
} 
According to Santos et al. [4], ergonomics was incorporated into the design process due to the need to consider human factors in designs. Rensink [5] stated that, although the human-machine interface in the design of oil companies is considered an integral part of engineering design, several maladjustments in operation and maintenance have occurred after the designs were implemented. This is due to the fact that designers and builders have different points that must be satisfied, including ergonomic factors. According to Rensink [5], designers are, by nature, more interested in the technical performance of their products, and do not operate or maintain installations after these enter into operation. Thus, they have insufficient knowledge about the physical and mental environment the user needs. Therefore, the application of ergonomic principles is easily overlooked during the design phase. Van Uden [6] adds that this occurs because final users are usually not consulted about decisions made during the design phases. However, Hendrick [7] points out that ergonomics is not simply common sense law among people, but requires the participation of qualified professionals.

The work reported here was developed at one of the refineries of Petrobras, which is responsible for $10 \%$ of the national production of petroleum derivatives. The refinery is currently engaged in several modernization projects, which, when they become operational, will not only generate economic benefits but will also contribute to the quality of its products [1]. New industrial units currently under construction will produce petroleum coke, propene, hexane, gasoline, diesel and liquid petroleum gas (LPG). Thus, the technical team in charge of Ergonomics Management at this refinery monitored the designs of these new units in order to implement ergonomics design at these sites.

\section{Materials and method}

The object of study here were 10 new units that are being implemented at a refinery of Petrobras. Six of them are production units, one is an industrial wastewater treatment unit, and three are utilities units. The production units will increase the refinery's production capacity and improve the quality of its products, such as gasoline and diesel oil. The utilities units, consisting of two boilers and one cooling tower, will provide support for the new production units. The industrial wastewater treatment unit will increase the refinery's current wastewater treatment capacity.
The analytical tool used in this study was Ergonomic Workplace Assessment. To use this too requires the participation of people familiar with the industrial processes involved. Moreover, it should be kept in mind that the description of a future task often does not coincide with the real activity that will be developed in industrial areas.

To oversee and follow up on the designs and construction work, multi-professional teams were set up composed of Petrobras employees and contract staff. These teams basically comprise specialists and users. The specialties include pipelines, civil engineering, automation, instrumentation, ergonomics, work safety and health. The user group consists of operation and maintenance technicians. This team is responsible for checking a variety of items under design and during the assembly of the units, including civil structures, the laying of pipelines, valve and blockage installations, equipment, instruments, ergonomics and user safety and health. With regard to ergonomics, the team is responsible for aligning the designs to ergonomic concepts and ensuring that predefined codes and standards are followed.

To this end, the team uses 3D electronic templates as graphic tools. The designers and engineers develop the designs of the units by means of these electronic templates. The templates are sent to the refinery and the group meets to analyze and discuss them. The meetings are held according to the schedule of each unit. During the meetings, the members of these teams meet to check the designs, discuss proposed design solutions, and make sure that they follow the technical codes, standards and specifications agreed under contract. All the claims of nonconformity made during the meetings at which the electronic templates are analyzed are recorded by the team on a single list and sent to the companies involved, for design adjustments. In addition to the analysis of the templates at these meetings, the team members have the electronic templates at their disposal for analysis on their own personal computers at their workstations.

In addition to the analysis of the graphic design to monitor and follow up on the assembly and implementation of the units, relatively frequent visits are made to the worksites, accompanied by their future users, for onsite checking of the requirements and solutions adopted. 


\section{Results and discussion}

A total of 455 ergonomic requirements were identified and recorded at the 10 units under analysis. Figure 1 shows the percentage of each type of ergonomic requirement identified in the analysis of 256 items at 5 production units.

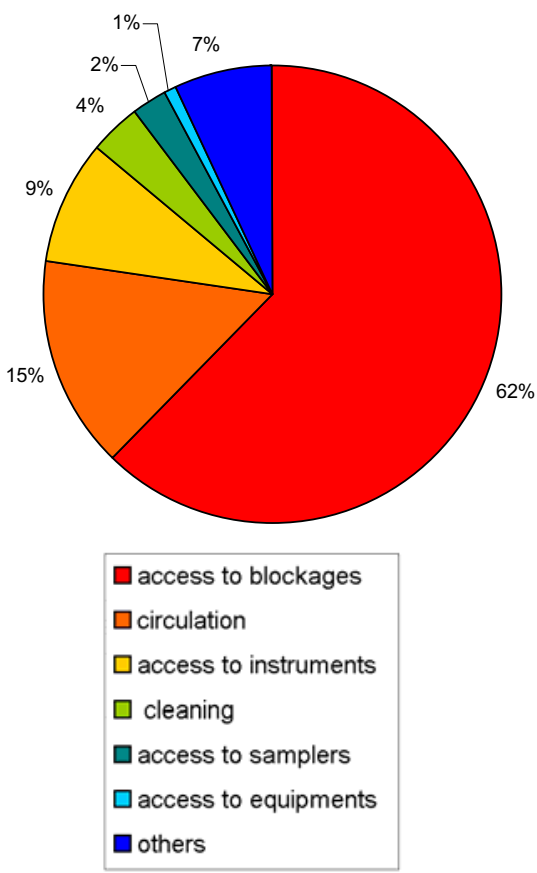

Figure 1

Characterization of the ergonomic requirements identified at 5 production units

As can be seen in Figure 1, most of the requirements identified involve the difficulty of access to blockages. Figure 2 illustrates an example of this type of requirement.

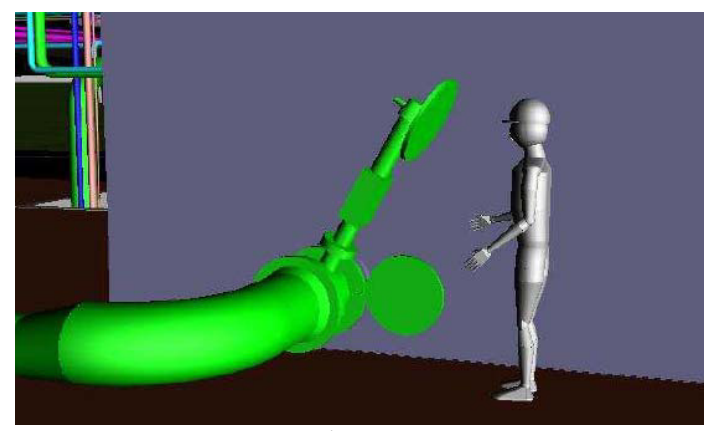

Figure 2

Example of an ergonomic requirement related to the difficult access to blockages
Figure 2 shows an image of the electronic template of one of the analyzed units. Based on the human scale in the graphic models, one can see that the blockage is outside the ideal area of reach. In addition to the visual observation, an analysis is made of the future activity at this site: who, when, and for what this blockage will be used. The answers to these questions are provided by the multidisciplinary teams, especially by the future users, i.e., operation and maintenance technicians. The technical team provides the necessary support in the stage of proposals for solutions. Figure 3 depicts the solution presented for this requirement.

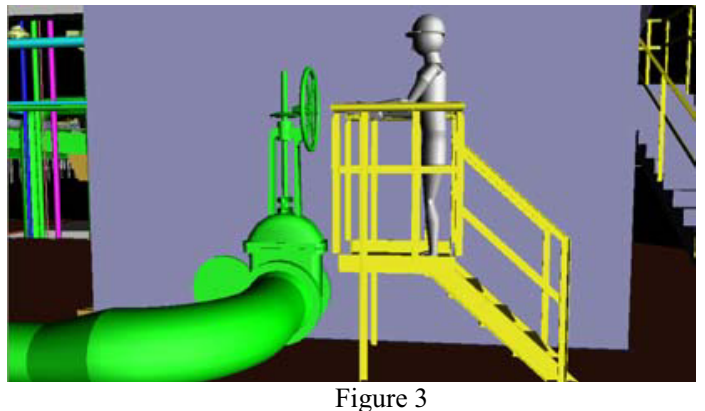

Solution proposed for the ergonomic requirement involving difficult access to blockage

Figure 1 indicates that $15 \%$ of the identified requirements involve the difficult circulation of people in the area of the units. This type of requirement is related principally with the direction and height of pipelines in areas of circulation. Figure 4 presents an example of this type of requirement: pipelines at inadequate heights in relation to the platform of the storage tank ladders.

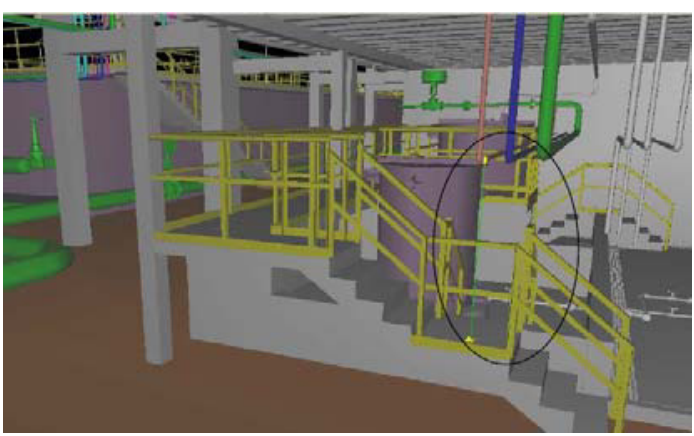

Figure 4

Example of an ergonomic requirement related to the difficult circulation of people 
The solution suggested for this requirement was to change the direction, arrangement and height of the pipelines, enabling people to pass through without risk of bumping into the pipelines. This solution is illustrated in Figure 5.

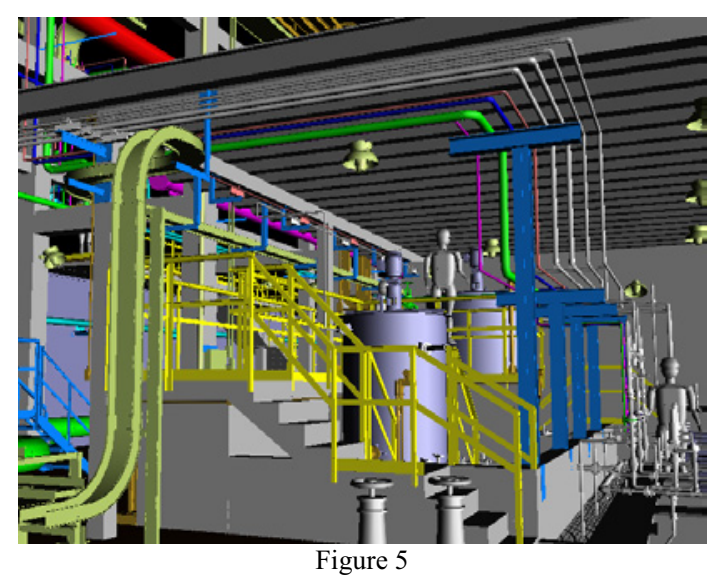

Solution proposed for the ergonomic requirement involving difficult circulation of people

Returning to Figure 1, note that $9 \%$ of the requirements involve difficult access to instruments, and $4 \%$ are related to cleaning in the industrial area.

The requirements of difficult access to instruments refer to the instruments for measuring temperature, outflow and pressure of the equipment and pipelines. These instruments may have gauges or indicators on the site, on a control console, or at both places. The ones whose gauges are located directly on equipment, access is done by operation and maintenance technicians. Those which have gauges only on a control console are accessed mainly for maintenance of the instrument, which can be programmed or on an emergency basis.

The items related with cleaning are due to the absence of suitable drainage points for discarding product close to drainage valves and product sampling ports. The lack of such drainage points causes product to spread over the floor of the unit, dirtying the boots of those who work there. Boots whose soles are smeared with oily products lose their traction and may cause accidents, as well as make it difficult to climb stairs and ladders.

\section{Conclusions}

The participation of the refinery's technical ergonomics team in monitoring the design of the new production, utilities and industrial wastewater treatment units revealed the feasibility of applying ergonomic design in a petrochemical plant.

This work highlighted the importance of the participation of a multidisciplinary team composed of specialists and future users in the identification of requirements and proposal of solutions, thus enabling the application of the analytical tool to assess future activity.

With regard to the types of ergonomic requirements identified here, they were found to be related to physical ergonomics, which is visible in the analysis of electronic templates. However, it proved to be more difficult to identify cognitive or organizational ergonomic requirements in the detailing phase of the units.

\section{References}

[1] http://www.petrobras.com.br/ acessado em 09/08/2011.

[2] Adorno, L. R. Levantamento de demandas ergonômicas em dez plantas petroquímicas brasileiras. Porto Alegre, 2004. 170f. Dissertação (Mestrado)- Universidade Federal do Rio Grande do Sul.

[3] Iida, I. Ergonomia: projeto e produção. São Paulo: Edgar Blucher, 2005, 2ed.

[4] Santos, V.; Zamberlan, M. C.; Pavard, B. Confiabilidade Humana e Projeto Ergonômico de Centros de Controle de Processos de Alto Risco. Rio de Janeiro: Synergia, 2009.

[5] Rensink, H. J. T. The Development of a Human Factors Engineering Strategy in Petrochemical Engineering and Projects: Part I. In: Proceedings at the Occupational Health Offshore Conference. Aberdeen, 2001. pp. 105-113.

[6] Van Uden, M. E. J. The Development of a Human Factors Engineering Strategy in Petrochemical Engineering and Projects: Part II. In: Proceedings at the Occupational Health Offshore Conference. Aberdeen, 2001. pp. 115-129.

[7] Hendrick, H.W. Applying Ergonomics to Systems: Some Documented "Lessons Learned". Applied Ergonomics, 2008 , 39 pp. 418-426. 